\title{
Adiponectin and 8-epi-PGF2 $a$ as intermediate influence factors in weight reduction after legumes consumption: a 12-week randomized controlled trial
}

\section{Youngmin Han}

Yonsei University

Jong Ho Lee

Yonsei University College of Human Ecology

Minjoo Kim ( $\nabla$ minjookim@hnu.kr)

Hannam University College of Life Science and Nano Technology https://orcid.org/0000-0002-42619333

\section{Research}

Keywords: legumes, obesity, body weight, adiponectin, 8-epi-PGF2a, insulin resistance

Posted Date: July 27th, 2020

DOI: https://doi.org/10.21203/rs.3.rs-46032/v1

License: (c) (i) This work is licensed under a Creative Commons Attribution 4.0 International License. Read Full License 


\section{Abstract \\ Background and Aims:}

The current nutritional intervention study was designed to determine the effect of legume on body weight in obese subjects.

\section{Methods}

Randomized controlled study of 12 weeks with 383 participants (body mass index $\geq 25 \mathrm{~kg} / \mathrm{m}^{2}$ ) was enrolled for the study. The intervention program consisted of replacing $1 / 3$ refined rice intake with legumes three times per day as a carbohydrate source in high fat diet group. In contrast, low fat diet group was recommended to eat as their usual diet.

\section{Results}

In high fat diet group, intake of energy and carbohydrate were lower, while the intake of fat and protein were higher. Mean weight loss at 12 weeks was $2.87 \pm 0.21 \mathrm{~kg}$ and $0.17 \pm 0.11 \mathrm{~kg}$ in the high fat diet group and low fat diet group, respectively, and was significantly different between groups $(P<0.001)$. HDLcholesterol and adiponectin were increased, while glucose, insulin, triglyceride, HOMA-IR index, and 8-epi$\mathrm{PGF}_{2 \mathrm{a}}$ were decreased at 12 weeks in the high fat diet group compared with baseline.

\section{Conclusions}

The conclusion is that the consumption of legumes may accelerate weight loss accompanied by regulation of adiponectin and 8-epi-PGF $2 a$ in obese subjects. Also, increases in plasma adiponectin induced by a larger amount of weight loss may relate to greater activation of insulin resistance.

\section{Trial registrations:}

NCT04392882 (Registered 19 May 2020 - Retrospectively registered, https://clinicaltrials.gov/ct2/show/NCT04392882?cond=NCT04392882\&draw=2\&rank=1)

\section{Background}

Obesity has been considered as one of the most serious health problems in Korea. As the prevalence of obesity, including severe obesity, has been increasing in Korea, a change of Asians' diagnostic standard for obesity seems to be needed. ${ }^{1}$ Obesity is a significant risk factor for many metabolic diseases like 
cardiovascular diseases (CVD), diabetes, and certain types of cancer, also associated with higher mortality.

Numerous data have shown a negative relationship between the consumption of legumes and obesity and metabolic syndrome. ${ }^{2-4}$ Alizadeh et al., indicated that consumption of a legumes-rich hypocaloric diet for six weeks reduced waist, hip, triceps, biceps, subscapular, and skinfold thicknesses among healthy premenopausal women with central obesity. ${ }^{5}$ Several cross-sectional and prospective studies have also supported the inverse association of legume consumption with obesity and CVD., 6 Besides the beneficial effects of non-soy legumes, a large body of documents is available regarding the impact of soy consumption on controlling and preventing cardiometabolic risks, improving features of the metabolic syndrome following a short-term period of soy consumption. ${ }^{8,9}$ Weight reducing effect of soy intake ${ }^{10}$ and favorable outcomes for type II diabetes, ${ }^{11,12}$ are some aspects of these beneficial effects. Several investigations have confirmed that chronic non-communicable conditions such as insulin resistance, diabetes, and CVD have a close link to obesity. ${ }^{13}$

For a long time, legumes are nutritionally recognized for their high protein content as well as for their soluble-fiber and other bioactive compounds. ${ }^{14}$ According to a study with an LC-MS-metabolomic approach, 43 compounds showed differences between the three different legumes (chickpea, lentil, white bean). Among them, 30 compounds were kind of polyphenols, mainly flavonol or flavanol, and others are a-galactosides, fatty acyls, prenol lipids, nucleoside, and organic compounds. ${ }^{15}$ Like this, there are various bioactive compounds in legumes. While the effects of dietary fiber on serum lipoproteins have received much attention, other bio-functional components in legumes could likely be involved in the cardioprotective results. ${ }^{16}$ Dietary soy protein's beneficial effects on lipid profiles are well documented, and several studies have suggested that soy intake aids against oxidative stress with antioxidant capacity. ${ }^{17,18}$

Here, we designed a nutritional intervention study to determine whether a diet enriched in legumes could accelerate weight loss accompanied by regulation of adiponectin and 8-epi-prostaglandin $\mathrm{F}_{2 a}$ (8-epi$\left.\mathrm{PGF}_{2 \mathrm{a}}\right)$.

\section{Methods}

\section{Subjects and study design}

A 12-week weight reduction program conducted by the National Leading Research Laboratory of Clinical Nutrigenetics/Nutrigenomics at Yonsei University. 400 subjects with a body mass index (BMI) of $25 \mathrm{~kg} / \mathrm{m}^{2}$ or higher based on Asia-Pacific guideline ${ }^{19}$ were recruited at the health promotion center of the National Health Insurance Corporation Ilsan Hospital in Goyang, Korea between March 2011 and December 2012. Based on personal health, medical history questionnaire, people who had a history of tvoe 2 diabetes. CVD. nsvchiatric problems. thyroid disorders, liver or kidney disease, and/or use of any Loading [MathJax]/jax/output/CommonHTML/jax.js 
medications (antihypertensive, lipid-lowering, antiplatelet, antidiabetic, etc.) were excluded. The paperbased informed consent forms were obtained and the Institutional Review Board of the Yonsei University approved the study protocol, which complied with the Declaration of Helsinki.

\section{Weight loss protocol and calorie intake}

One week before starting the 12-week program, the enrolled subjects' usual diet information was obtained using both a 24-h recall method and a semi-quantitative food frequency questionnaire. Registered dietitian gave written and verbal instructions on completion of a 3-day (2 weekdays and one weekend) dietary record.

After a week, the intervention started. Individually-planned diets for each subject were provided based on their dietary data previously obatained before, and Korean Recommended Dietary Allowance (Korean RDA, Korean Nutrition Society, Seoul, Korea). The intervention program consisted of replacing $1 / 3$ refined rice intake with legumes three times per day as a carbohydrate source in high-fat diet group (HFD) while lowfat diet group (LFD) were recommended to eat as their usual diet and increased vegetable intake to at least six units (30-70 g/unit) per day. The subjects were assigned physical activity consisting of a regular 30-min walk after dinner each day, also instructed to record their physical activity for 24-h every four weeks.

Participants' compliance was checked by the dietician, interviewing them biweekly by telephone. They were interviewed whether they were following the program well, including dietary intake and physical activity. Dietary energy values and nutrient content were calculated using the Computer-Aided Nutritional analysis program (CAN-pro 2.0, Korean Nutrition Society, Seoul, Korea) based on 3-day food records. Basal metabolic rate, physical activity for $24-\mathrm{h}$, and specific dynamic action of food were considered for total energy expenditure ( $\mathrm{kcal} / \mathrm{day}$ ) of each subject.

\section{Anthropometric parameters, blood pressure, and blood collection}

Body weights and heights were measured for BMI (kilograms per square meter) calculating. Blood pressure (BP) was measured in the left arm of seated patients with an automatic BP monitor (TM-2654; A\&D, Tokyo, Japan) after resting. After 12-h fast, venous blood specimens were collected in EDTA-treated or untreated tubes. Separated plasma and serum were stored at $-70^{\circ} \mathrm{C}$ until used in further analysis.

\section{Serum glucose, insulin, lipid profiles, serum high sensitivity C-reactive protein, and urinary 8-epi-prostaglandin $\mathrm{F}_{2 a}$}

Detailed information about assessments of fasting glucose, insulin, serum high sensitivity C-reactive protein (hs-CRP) was described in our previous study ${ }^{20}$. Analysis of triglycerides and total-cholesterol performed using a Hitachi 7150 Autoanalyzer (Hitachi Ltd., Tokyo, Japan). HDL-cholesterol separated from participated apoB-containing lipoproteins with dextran sulfate-magnesium was measured 
$\mathrm{mg} / \mathrm{dL}$ subjects. The compound 8-epi-PGF $2 \mathrm{a}$ was measured in urine using an enzyme immunoassay (BIOXYTECH urinary 8-epi-PGF 2 TM Assay kit, OXIS International Inc., Portland, OR).

\section{Homeostasis-model assessment of insulin resistance and adiponectin}

Insulin resistance (IR) was calculated by the homeostasis-model assessment (HOMA): [fasting insulin $(\mu \mathrm{lU} / \mathrm{mL}) \times$ fasting glucose $(\mathrm{mmol} / \mathrm{L})] / 22.5$. Plasma adiponectin concentration was measured by an enzyme immunoassay (Human Adiponectin ELISA kit, B-Bridge International Inc., CA, USA) and Victor2 (Perkin Elmer Life Sciences, Turku, Finland).

\section{Statistical analyses}

We performed statistical analyses using SPSS ver 25.0 (SPSS Inc., Chicago, IL, USA). Before statistical analyses, the skewed variables were logarithmically-transformed. To evaluate differences of clinical variables levels between two groups, independent t-tests were used. For analyzing differences between baseline/12-week follow-up time scale, paired t-tests were used. Pearson's correlation coefficients were used to investigate the relationships between variables over time.

\section{Results}

Among the enrolled subjects $(n=400), 17$ dropped out, 8 dropped out in HFD group and 9 dropped out in LFD group by the end of the 12-week dietary intervention for personal reasons or poor compliance, leaving 383 subjects.

\section{Clinical characteristics and nutrient intake before and after dietary intervention}

After 12-week follow-up in HFD group, weight $(P<0.001)$, systolic blood pressure (SBP) $(P=0.037)$, diastolic blood pressure (DBP) $(P=0.001)$, and daily nutrient intake, especially, energy intake $(P<0.001)$ and carbohydrate intake $(P<0.001)$ were decreased (Table 1$)$. However, total energy expenditure (TEE) $(P<0.001)$, protein $(P=0.027)$, fat $(P<0.001)$, and fiber $(P=0.003)$ intake were increased. These result patterns were not showed in the LFD group after the intervention, except TEE $(P<0.001)$ and fiber intake $(P=0.037)$ were increased. Between HFD and LFD group, weight, BMI, energy intake, carbohydrate, and fat intake showed significant after 12-week follow-up and changed values (difference from baseline), while SBP showed significant only in 12-week (Table 1).

\section{Serum glucose, insulin, lipid profiles, $h s-C R P$, and 8-epi-PGF $2 a$}

In HFD group, glucose $(P<0.001)$, insulin $(P<0.001)$, and 8-epi-PGF $2 a(P=0.021)$ had decreased after the 12- 
group, there were no changes and significant differences shown in LFD group. Compared with HFD and LFD groups, HDL-cholesterol ( $P=0.003)$, fasting glucose $(P=0.039)$, and insulin $(P<0.001)$ were significantly different at the end of the 12-week intervention period. Besides, the changed value of insulin $(P=0.020)$ was significantly different between the two groups; also, 8-epi-PGF $2 \mathrm{a}$ tended to different after the 12-week intervention period (Table 2).

\section{Triglyceride, HOMA-IR index, and adiponectin}

Triglyceride $(P<0.001)$ and HOMA-IR index $(P<0.001)$ significantly decreased, and adiponectin $(P<0.001)$ increased at the end of the 12-week follow-up in HFD group, while LFD group had not shown any differences after a dietary intervention (Figure 1). Between HFD and LFD group, the HOMA-IR index was significantly different at follow-up $(P<0.001)$ and difference from baseline $(P=0.016)$, as similar to adiponectin change was significantly different at follow-up $(P<0.001)$ and difference from baseline $(P<0.001)$. In the case of triglyceride, only at the end of the 12-week follow-up tended to differentiate between two groups (Figure 1).

\section{Correlations among changes in BMI, HDL-cholesterol, HOMA-IR index, and adiponectin}

In total, 383 subjects, changes in BMI and HDL-cholesterol ( $r=-0.146, P=0.004)$, and changes in $\mathrm{BMI}$ and adiponectin negatively correlated $(r=-0.314, P<0.001)$ in a linear manner (Figure 2$)$. Changes in $B M I$ positively correlated with changes HOMA-IR index $(r=0.154, P=0.003)$. In HFD group, only changes in BMI negatively correlated with changes in adiponectin $(r=-0.271, P=0.003)$. In the case of LFD group, changes $\mathrm{BMI}$ and HDL-cholesterol negatively correlated $(r=-0.161, P=0.016)$, while changes $B M I$ tended positively associated with changes HOMA-IR index and negatively correlated with changes adiponectin (Figure 2).

\section{Relationship among adiponectin, hs-CRP, 8-epi-PGF ${ }_{2 a}$ anthropometric, and biochemical markers before and after 12-week intervention}

All subjects in baseline, though adiponectin negatively correlated with weight $(\mathrm{r}=-0.150, P=0.009)$, triglyceride $(\mathrm{r}=-0.202, P<0.001)$, glucose $(\mathrm{r}=-0.140, P=0.015)$, insulin $(\mathrm{r}=-0.115, P=0.048)$, HOMA-IR index $(\mathrm{r}=-0.150, P=0.010)$, and hs-CRP $(\mathrm{r}=-0.129, P=0.026)$, positively correlated with HDL-cholesterol $(\mathrm{r}=0.162$, $P<0.001)$ and $\mathrm{LDL}$-cholesterol $(\mathrm{r}=0.162, P=0.005)$. At the end of the 12-week intervention, adiponectin negatively correlated with triglyceride $(\mathrm{r}=-0.349, P<0.001), \mathrm{HDL}$-cholesterol $(\mathrm{r}=0.189, P=0.042)$, insulin $(\mathrm{r}=-0.236, P=0.012)$, and HOMA-IR $(\mathrm{r}=-0.215, P=0.022)$ in HFD group. However, in LFD group, adiponectin negatively correlated with triglyceride and glucose ( $\mathrm{r}=-0.193, P=0.029 ; \mathrm{r}=0.204, P=0.021$, respectively), and positively correlated with HDL-cholesterol $(r=0.352, P<0.001)$ after follow-up. In case of hs-CRP, insulin 
correlated, and positively tended to correlated with triglyceride in HFD group at 12-week period. These result patterns were shown in LFD group as similar as HFD group after intervention. Furthermore, 8-epi$\mathrm{PGF}_{2 \mathrm{a}}$ was positively correlated with glucose, insulin, and HOMA-IR $(\mathrm{r}=0.264, P=0.002 ; \mathrm{r}=0.219, P=0.010$; $r=0.264, P=0.002$, respectively) in HFD group at the end of the 12-week intervention, also, these relationships were shown in LFD group likewise HFD group.

\section{Discussion}

The present study suggests that a 12-week legume enriched-diet may improve clinical variables in obese subjects. After 12 weeks, legume enriched-diet groups had significant reductions in body weight and BMI. However, the significant differences were not observed in the control group who intake the usual diet with increased vegetable. According to the Korea Health Statistics 2011: Korea National Health and Nutrition Examination Survey (KNHANES V-2), populations who live in cities consume approximately $19.6 \%$ of total calories from fat. Based on this data, our results showed significantly different between HFD and LFD group after a 12-week intervention ( $22.0 \pm 0.29$ vs. $19.7 \pm 0.21)$.

Our results are partly following some clinical studies. ${ }^{21}$ Papanikolaou and Fulgoni ${ }^{22}$ reported a relationship between bean consumption and obesity risk in about 8000 adult participants in the NHANES 1999-2002 using data obtained by the 24-h dietary recall. They found that people who had consumed a variety of beans or baked beans presented significantly low body weight compared with those who had not consumed beans. Also, the odds of being obese $\left(\mathrm{BMl}>30 \mathrm{~kg} / \mathrm{m}^{2}\right)$ was significantly lower in variety bean and baked bean consumers, (odds ratio $=0.78$ and 0.77 , respectively). Venn et al. showed a slightly different result. This has shown that the incorporation of pulses and whole grain foods into a weight loss program resulted in an essential reduction in waist circumference compared to the control diet, although weight loss was no difference between groups. ${ }^{23}$ Also, no relationship between legume consumption and the odds of metabolic syndrome is reported in a recent meta-analysis study. ${ }^{24}$

Adiponectin identified as an adipocytokine in the human adipose tissue has antiatherosclerotic and antidiabetic properties. Blood levels of adiponectin are low in metabolic syndrome including obesity, diabetes, and CVD. Several studies have reported that weight loss in massively obese subjects is associated with serum adiponectin concentration increase. ${ }^{26,27}$ The present study demonstrated that a decrease in BMI correlated with an increase in adiponectin at an obese subject. Yannakoulia et al. noted that whole grain intake has an association with high adiponectin levels. In a cross-sectional study of 220 healthy Mediterranean women, adherence to a dietary pattern characterized by high consumption of legumes, whole grain cereals, and low-fat dairy products was positively associated with adiponectin levels after controlling potential confounders. ${ }^{25}$ Adiponectin activates peroxisome proliferator-activated receptor (PPAR)- $\alpha$ and activated protein kinases (AMPK). PPAR- $a$ and AMPK increase the utilization of fatty acids, glucose in skeletal muscle. Their control of gluconeogenesis, glycogenolysis, and lipid content in the liver can lower insulin resistance. Our results showed plasma adiponectin levels has a negative correlation with body weight, HOMA-IR, and hs-CRP and positive relationship with HDL-cholesterol, which is the same Loading [MathJax]/jax/output/CommonHTML/jax.js 
as previous studies. ${ }^{28,29}$ Also, the HFD group had significant decreases in HOMA-IR and significant increases in adiponectin levels after the 12-week intervention. These data suggest that a more substantial amount of weight loss could affect increases in plasma adiponectin which may control insulin and glucose metabolism normally.

To further assess the effect of the dietary legumes on oxidative stress, urinary excretion of 8-epi-PGF $2 a$ was measured. ${ }^{30,31}$ As this marker decreased after the intervention, a diet enriched in legumes showed effects by mitigating oxidative stress. Accumulated fat induce production of reactive oxygen species (ROS) and lipid peroxidation by-products. These compounds are closely related to pro-inflammatory state with increasing inflammatory cytokines secretion, and macrophage infiltration. To sum up, our outcome appeared in addition to the recognized beneficial effect associated with weight loss. Another possible contribution to the reduction in oxidative stress is natural antioxidants in legumes. Several studies measured the direct impact of legumes on oxidative stress in vitro. Nicola ${ }^{32}$ demonstrated lentils' antioxidant capacity using DPPH, ABTS assay, although this effect decreased slightly after the boiling process.

The point that dietary intake information of participants was collected from self-reports is a limitation of our study. However, measurement errors from self-reported nutritional intake and lifestyle variables have been shown to be relatively small. ${ }^{33}$

\section{Conclusions}

Our data suggest that legumes enriched diet may help control body weight in overweight and obese subjects with associated with adiponectin and 8-epi-PGF $2 a$. Also, increases in plasma adiponectin induced by a more considerable amount of weight loss may relate to greater activation of insulin resistance. Further studies, including more extensive clinical studies with subjects who are extremely obese and have been obese for more extended periods, are needed to confirm the beneficial effects of legume on weight reduction.

\section{Abbreviations}

8-epi-PGF $2 a$ : 8-epi-prostaglandin $\mathrm{F}_{2 a}$; AMPK: activated protein kinase; BMI: Body mass index; BP: Blood pressure; CVD: Cardiovascular disease; DBP: Diastolic blood pressure; HFD: High fat diet group; HOMA: Homeostasis-model assessment; hs-CRP: High sensitivity C-reactive protein; IR: Insulin resistance; LFD: Low fat diet group; PPAR: peroxisomes proliferator-activated receptor; SBP: Systolic blood pressure; TEE: Total energy expenditure

\section{Declarations}

Ethics approval and consent to participate: The Institutional Review Board of the Yonsei University Loading [MathJax]/jax/output/CommonHTML/jax.js 
Consent for publication: The paper-based informed consent forms, stored in a document system after obtaining the necessary signatures, were used to record the intent and identify the will to join in the research.

Availability of data and materials: The datasets generated during and/or analyzed during the current study are available from the corresponding author on reasonable request.

Competing interests: The authors declare that they have no competing interests.

Funding: This research was supported by Basic Science Research Program through the National Research Foundation of Korea funded by the Ministry of Science and ICT (2012M3A9C4048762 and NRF2017R1C1B2007195) and Ministry of Education (NRF-2019R1I1A2A01061731).

Authors' contributions: $\mathrm{YH}, \mathrm{JHL}$, and $\mathrm{MK}$ analyzed data; $\mathrm{JHL}$ and $\mathrm{MK}$ developed the study protocol and design; all of authors read, commented on, and contributed to the manuscript; JHL and MK provided research funding and developed the study protocol. MK is the guarantor of this work, had full access to all data in the study, and takes responsibility for the integrity of the data and the accuracy of the data analysis.

Acknowledgments: The authors thank the research volunteers who participated in the studies described in this article.

\section{References}

1. Yoon YS, Oh SW. Recent Shift of Body Mass Index distribution in Korea: a population-based Korea National Health Insurance Database. J Korean Med Sci. 2017 Mar;32(3):434-438.

2. Winham DM, Hutchins AM. Baked bean consumption reduces serum cholesterol in hypercholesterolemic adults. Nutr Res 2007 Jul;27(7):380-6.

3. Villegas R, Gao YT, Yang G, Li HL, Elasy TA, Zheng W, et al. Legume and soy food intake and the incidence of type 2 diabetes in the Shanghai Women's Health Study. Am J Clin Nutr. 2008 Jan;87(1):162-7.

4. Hosseinpour-Niazi S, Mirmiran P, Amiri Z, Hosseini-Esfahani F, Shakeri N, Azizi F. Legume intake is inversely associated with metabolic syndrome in adults. Arch Iran Med. 2012 Sep;15(9):538-44.

5. Alizadeh M, Daneghian S, Ghaffari A, Ostadrahimi A, Safaeiyan A, Estakhri R, et al. The effect of hypocaloric diet enriched in legumes with or without $L$ - arginine and selenium on anthropometric measures in central obese women. J Res Med Sci. 2011 Nov;15(6):331-43.

6. Stoll G, Bendszus M. Inflammation and atherosclerosis: novel insights into plaque formation and destabilization. Stroke. 2006 Jul;37(7):1923-32.

7. Cushman M, Arnold AM, Psaty BM, Manolio TA, Kuller LH, Burke GL, et al. C-reactive protein and the 10-year incidence of coronary heart disease in older men and women: the cardiovascular health 
8. Azadbakht L, Esmaillzadeh A. Soy and cardio-metabolic abnormalities: an update. J Res Med Sci. 2008 Mar-Apr;13(2):88-96.

9. Azadbakht L, Esmaillzadeh A. A cross-over trial on soy intake and serum leptin levels in women with metabolic syndrome. J Res Med Sci. 2010 Nov;15(6):317-23.

10. Jang EH, Moon JS, Ko JH, Ahn CW, Lee HH, Shin JK, et al. Novel black soy peptides with antiobesity effects: activation of leptin-like signaling and AMP-activated protein kinase. Int J Obes (Lond). 2008 Jul;32(7):1161-70.

11. Azadbakht L, Esmaillzadeh A. Soy-protein consumption and kidney-related biomarkers among type 2 diabetics: a crossover, randomized clinical trial. J Ren Nutr. 2009 Nov;19(6):479-86.

12. Azadbakht L, Atabak S, Esmaillzadeh A. Soy protein intake, cardiorenal indices, and C-reactive protein in type 2 diabetes with nephropathy: a longitudinal randomized clinical trial. Diabetes Care. 2008 Apr;31(4):648-54.

13. Dixon JB. The effect of obesity on health outcomes. Mol Cell Endocrinol. 2010 Mar;316(2):104-8.

14. Kim H, Choi E, Kim HS, Choi C, Choi S, Kim S, et al. Germinated soy germ extract amilorates obesity through beige fat oxidation. Food Funct. 2019 Feb;20:10(2):836-48.

15. Llorach R, Favaria C, Alonsoa D, Garcia-Aloy M, Andres-Lacueva C, Urpi-Sarda M. Comparative metabolite fingerprinting of legumes using LC-MS-based untargeted metabolomibs. Food Res Int. 2019 Dec;126:108666.

16. Ruscica M, Pavanello C, Gandini S, Gomaraschi M, Vitali C, Macchi C, et al. Effect of soy on metabolic syndrome and cardiovascular risk factors: a randomized controlled trial. Eur J Nutr. 2018 Mar,57(2):499-511.

17. Jenkins DJ, Kendall CW, Vidgen E, Vuksan V, Jackson CJ, Augustin LS, et al. Effect of soy-based breakfast cereal on blood lipids and oxidized low-density lipoprotein. Metabolism. 2000 Nov;49(11):1496-500.

18. Wiseman H, O'Reilly JD, Adlercreutz H, Mallet Al, Bowey EA, Rowland IR, et al. Isoflavone phytoestrogens consumed in soy decrease $F(2)$-isoprostane concentrations and increase resistance of low-density lipoprotein to oxidation in humans. Am J Clin Nutr. 2000 Aug;72(2):395-400.

19. WHO Expert Consultation. Appropriate body-mass index for Asian populations and its implications for policy and intervention strategies. Lancet. 2004 Jan;363(9403):157-63.

20. Kim M, Kim M, Yoo HJ, Lee SY, Lee SH, Lee JH. Age-specific determinants of pulse wave velocity among metabolic syndrome components, inflammatory markers, and oxidative stress. J Atheroscler Thromb. 2018 Feb;25(2):178-85.

21. Darmadi-Blackberry I, Wahlqvist ML, Kouris-Blazos A, Steen B, Lukito W, Horie Y, et al. Legumes: the most important dietary predictor of survival in older people of different ethnicities. Asia Pac J Clin Nutr. 2004;13(2):217-20.

22. Papanikolaou Y, Fulgoni VL III. Bean consumption is associated with greater nutrient intake, reduced systolic blood pressure, lower body weight, and a smaller waist circumference in adults: results from 
the National Health and Nutrition Examination Survey 1999-2002. J Am Coll Nutr. 2008 Oct;27(5):569-76.

23. Venn BJ, Perry T, Green TJ, Skeaff CM, Aitken W, Moore NJ, et al. The effect of increasing consumption of pulses and whole-grains in obese people: a randomized controlled trial. J Am Coll Nutr. 2010 Aug;29(4):365-72.

24. Jiang Y, Zhang J, Liu Y, Chang Q, Zhao Y, Wu Q. Relationship between legume consumption and metabolic syndriome: A systematic review and meta-analysis of observational studies. Nutr Metab Cardiovas Dis. 2020 Mar;30(3):384-92.

25. Yang WS, Lee WJ, Funahashi T, Tanaka S, Matsuzawa Y, Chao CL, et al. Weight reduction increases plasma levels of an adipose-derived anti-inflammatory protein, adiponectin. J Clin Endocrinol Metab. 2001 Aug;86(8):3815-9.

26. Ng TWK, Watts GF, Barrett PH, Rye KA, Chan DC. Effect of weight loss on LDL and HDL kinetics in the metabolic syndrome: associations with changes in plasma retinol-binding protein-4 and adiponectin levels. Diabetes Care. 2007 Nov;30(11):2945-50.

27. Yannakoulia M, Yiannakouris N, Melistas L, Kontogianni MD, Malagaris I, Mantzoros C. A dietary pattern characterized by high consumption of whole-grain cereals and low-fat dairy products and low consumption of refined cereals is positively associated with plasma adiponectin levels in healthy women. Metabolism. 2008 Jun;57(6):824-30.

28. Menzaghi C, Ercolino T, Di Paola R, Berg AH, Warram JH, Schere PE, et al. A haplotype at the adiponectin locus is associated with obesity and other features of the insulin resistance syndrome. Diabetes. 2002 Jul;51(7):2306-12.

29. Huang KC, Lue BH, Yen RF, Shen CG, Ho SR, Tai TY, et al. Plasma adiponectin levels and metabolic factors in nondiabetic adolescents. Obes Res. 2004 Jan;12(1):119-24.

30. Milne GL, Musiek ES, Morrow JD. F2-isoprostanes as markers of oxidative stress in vivo: An overview. Biomarkers. 2005 Nov; 10(Suppl 1):S10-23.

31. Morrow JD. The isoprostanes-unique products of arachidonate peroxidation: Their role as mediators of oxidant stress. Curr Pharm Des. 2006;12(8):895-902.

32. Landi N, Pacifico S, Piccolella S, Giuseppe AMAD, Mezzacapo MC, Ragucci S, et al. Valle Agricola lentil, an unknown lentil (lens culinaris medik.) seed from southern Italy as a novel antioxidant and prebiotic source. Food Funct. 2015 Sep;6(9):3155-64.

33. Rimm EB, Giovannucci EL, Stampfer MJ, Colditz GA, Litin LB, Willett WC. Reproducibility and validity of an expanded self-administered semi-quantitative food frequency questionnaire among male health professionals. Am J Epidemiol. 1992 May;135(10):1114-26.

\section{Tables}

Table 1. Clinical characteristics and macronutrient indices at baseline and at the end of the Loading [MathJax]/jax/output/CommonHTML/jax.js riod of the participants

Page $11 / 15$ 


\begin{tabular}{|c|c|c|c|}
\hline & $\begin{array}{l}\text { High fat diet } \\
(\mathrm{n}=160)\end{array}$ & $\begin{array}{l}\text { Low fat diet } \\
\quad(\mathrm{n}=223)\end{array}$ & $P$-value \\
\hline Male/female (\%) & $42.5 / 57.5$ & $41.7 / 58.3$ & 0.876 \\
\hline Age (year) & $49.4 \pm 1.12$ & $48.5 \pm 0.85$ & 0.530 \\
\hline \multicolumn{4}{|l|}{ Weight (kg) } \\
\hline Before & $74.5 \pm 0.85$ & $74.1 \pm 0.69$ & 0.758 \\
\hline After & $71.6 \pm 0.85^{* * *}$ & $74.0 \pm 0.68$ & 0.029 \\
\hline Change & $-2.87 \pm 0.21$ & $-0.17 \pm 0.11$ & $<0.001$ \\
\hline \multicolumn{4}{|c|}{ Body mass index $\left(\mathrm{kg} / \mathrm{m}^{2}\right)$} \\
\hline Before & $27.6 \pm 0.21$ & $27.4 \pm 0.16$ & 0.329 \\
\hline After & $26.5 \pm 0.21^{* * *}$ & $27.3 \pm 0.16$ & 0.003 \\
\hline Change & $-1.09 \pm 0.08$ & $-0.06 \pm 0.04$ & $<0.001$ \\
\hline \multicolumn{4}{|c|}{ Systolic BP (mmHg) } \\
\hline Before & $125.2 \pm 1.30$ & $128.6 \pm 1.21$ & 0.067 \\
\hline After & $122.8 \pm 1.23^{*}$ & $128.3 \pm 1.05$ & 0.001 \\
\hline Change & $-2.41 \pm 1.14$ & $-0.21 \pm 0.98$ & 0.145 \\
\hline \multicolumn{4}{|c|}{ Diastolic BP (mmHg) } \\
\hline Before & $79.5 \pm 0.85$ & $79.9 \pm 0.77$ & 0.720 \\
\hline After & $76.8 \pm 0.80^{* *}$ & $78.6 \pm 0.77$ & 0.096 \\
\hline Change & $-2.63 \pm 0.77$ & $-1.29 \pm 0.66$ & 0.187 \\
\hline \multicolumn{4}{|c|}{ Total energy expenditure (kcal/d) } \\
\hline Before & $2218.5 \pm 29.6$ & $2192.1 \pm 23.4$ & 0.479 \\
\hline After & $2308.1 \pm 31.2^{* * *}$ & $2265.3 \pm 24.2^{* * *}$ & 0.273 \\
\hline Change & $89.6 \pm 12.8$ & $73.3 \pm 12.3$ & 0.366 \\
\hline \multicolumn{4}{|c|}{$\begin{array}{l}\text { Estimates of daily nutrient intake } \\
\text { Energy intake (kcal) }\end{array}$} \\
\hline Before & $2389.5 \pm 27.9$ & $2380.0 \pm 29.8$ & 0.824 \\
\hline After & $2147.1 \pm 39.1^{* * *}$ & $2333.2 \pm 30.7$ & $<0.001$ \\
\hline Change & $-242.4 \pm 42.5$ & $-52.1 \pm 34.6$ & 0.001 \\
\hline \multicolumn{4}{|c|}{ Carbohydrate (\%) } \\
\hline Before & $60.1 \pm 0.47$ & $60.6 \pm 0.32$ & 0.363 \\
\hline After & $57.7+0.41^{* * *}$ & $59.9 \pm 0.40$ & $<0.001$ \\
\hline Change & $-2.35 \pm 0.52$ & $-0.69 \pm 0.51$ & 0.027 \\
\hline \multicolumn{4}{|l|}{ Protein (\%) } \\
\hline Before & $20.5 \pm 0.39$ & $20.3 \pm 0.25$ & 0.699 \\
\hline After & $21.5 \pm 0.38^{*}$ & $21.3 \pm 0.51$ & 0.820 \\
\hline Change & $0.99 \pm 0.44$ & $1.03 \pm 0.56$ & 0.968 \\
\hline \multicolumn{4}{|l|}{ Fat $(\%)$} \\
\hline Before & $19.5 \pm 0.41$ & $19.7 \pm 0.27$ & 0.729 \\
\hline After & $22.0+0.29^{* * *}$ & $19.7 \pm 0.21$ & $<0.001$ \\
\hline Change & $2.47 \pm 0.43$ & $-0.04 \pm 0.32$ & $<0.001$ \\
\hline \multicolumn{4}{|l|}{ Fiber (g) } \\
\hline Before $\oint$ & $11.8 \pm 0.52$ & $12.1 \pm 0.60$ & 0.176 \\
\hline After $\oint$ & $14.5 \pm 0.69^{* *}$ & $14.1 \pm 0.65^{*}$ & 0.120 \\
\hline Change & $2.77 \pm 0.72$ & $2.05 \pm 0.58$ & 0.431 \\
\hline
\end{tabular}

Means \pm SEM. ${ }^{\oint}$ tested by logarithmic transformation, ${ }^{*} P<0.05,{ }^{* *} P<0.01,{ }^{* * *} P<0.001$ compared with baseline values in each diet group tested by paired $t$-test. $P$-values derived from independent $t$-test. 
Table 2. Effects of dietary intervention on lipid profiles, glucose, insulin, hs-CRP, and 8-epi$\mathrm{PGF}_{2 \alpha}$ at baseline and 12-week follow-up

\begin{tabular}{|c|c|c|c|}
\hline & $\begin{array}{l}\text { High fat diet } \\
(\mathrm{n}=160)\end{array}$ & $\begin{array}{c}\text { Low fat diet } \\
(\mathrm{n}=223)\end{array}$ & $P$-value \\
\hline \multicolumn{4}{|c|}{ LDL-cholesterol (mg/dL) } \\
\hline Before $\oint$ & $111 . .0 \pm 2.44$ & $114.6 \pm 2.60$ & 0.918 \\
\hline After $\oint$ & $108.0 \pm 2.61$ & $113.1 \pm 2.50$ & 0.196 \\
\hline Change & $-2.99 \pm 2.03$ & $-1.50 \pm 2.17$ & 0.616 \\
\hline \multicolumn{4}{|c|}{ HDL-cholesterol (mg/dL) } \\
\hline Before $\oint$ & $45.6 \pm 0.98$ & $43.7 \pm 0.78$ & 0.165 \\
\hline After $\oint$ & $48.1 \pm 0.88^{* * *}$ & $44.8 \pm 0.80$ & 0.003 \\
\hline Change & $2.48 \pm 0.76$ & $1.55 \pm 0.63$ & 0.342 \\
\hline \multicolumn{4}{|c|}{ Glucose $(\mathrm{mg} / \mathrm{dL})$} \\
\hline Before ${ }^{\oint}$ & $97.4 \pm 1.82$ & $99.3 \pm 1.78$ & 0.531 \\
\hline After $\oint$ & $93.8 \pm 2.65^{* * *}$ & $97.9 \pm 1.99$ & 0.039 \\
\hline Change & $-3.59 \pm 1.94$ & $-1.41 \pm 1.63$ & 0.388 \\
\hline \multicolumn{4}{|c|}{ Insulin (uIU/mL) } \\
\hline Before $\oint$ & $11.8 \pm 0.54$ & $10.8 \pm 0.36$ & 0.446 \\
\hline After $\oint$ & $9.17 \pm 1.07^{* * *}$ & $10.6 \pm 0.52$ & $<0.001$ \\
\hline Change & $-2.58 \pm 0.96$ & $-0.17 \pm 0.53$ & 0.020 \\
\hline \multicolumn{4}{|c|}{ Free fatty acid (uEq/L) } \\
\hline Before $\oint$ & $532.4 \pm 1.8 .0$ & $524.9 \pm 17.3$ & 0.572 \\
\hline After $\oint$ & $507.5 \pm 20.1$ & $503.0 \pm 16.3$ & 0.952 \\
\hline Change & $-24.8 \pm 18.8$ & $-21.9 \pm 17.7$ & 0.911 \\
\hline \multicolumn{4}{|c|}{$1_{\mathrm{hs}-\mathrm{CRP}(\mathrm{mg} / \mathrm{dL})}$} \\
\hline Before ${ }^{\oint}$ & $1.97 \pm 0.08$ & $2.09 \pm 0.09$ & 0.707 \\
\hline After $\oint$ & $1.89 \pm 0.09$ & $2.09 \pm 0.11$ & 0.854 \\
\hline Change & $-0.19 \pm 0.07$ & $0.00 \pm 0.10$ & 0.132 \\
\hline \multicolumn{4}{|c|}{ 8-epi-PGF $2 \alpha(\mathrm{pg} / \mathrm{mg}$ creatinine) } \\
\hline Before ${ }^{\oint}$ & $1330.5 \pm 81.9$ & $1346.4 \pm 66.7$ & 0.504 \\
\hline After $\oint$ & $1216.6 \pm 80.7^{*}$ & $1299.2 \pm 65.5$ & 0.077 \\
\hline Change & $-56.3 \pm 75.7$ & $-36.7 \pm 65.9$ & 0.844 \\
\hline
\end{tabular}

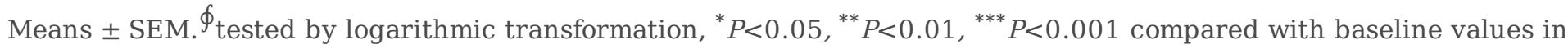
each diet group tested by paired $t$-test. $P$-values derived from independent $t$-test. ${ }^{1}$ hs-CRP $=$ high sensitivity $\mathrm{C}$ reactive protein.

\section{Figures}


Triglyceride $^{\phi}$

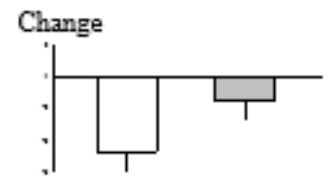

(nmol/mL/min)

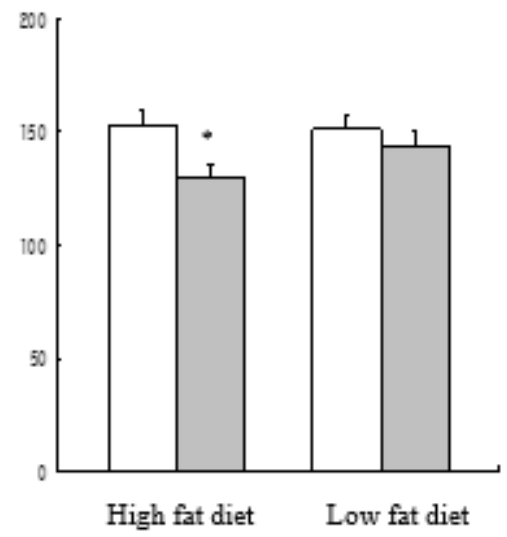

HOMA-IR ${ }^{\phi}$
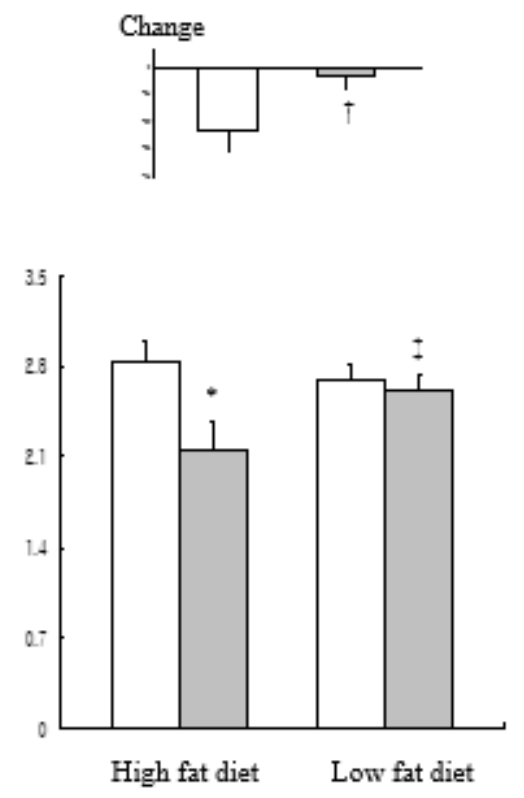

Adiponectin

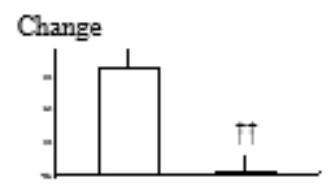

(ng/mL)

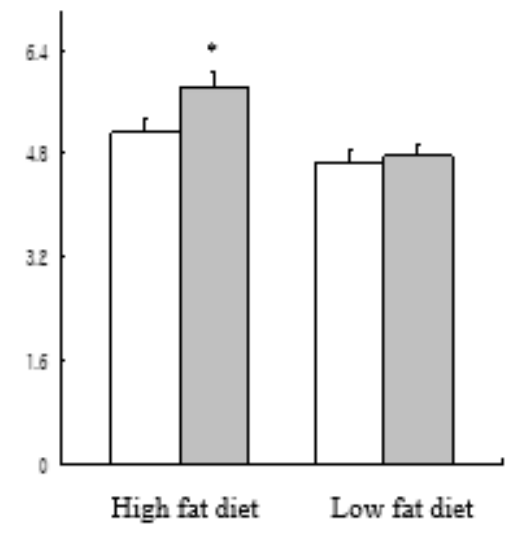

Figure 1

Effects of legume consumption on triglyceride, HOMA-IR index, and adiponectin before $(\square)$ and after 12week $(\boldsymbol{\square})$ dietary intervention Means \pm S.E., $§$ Tested by log-transformed. ${ }^{*} P<0.001$ compared to baseline values in each group tested by paired t-test. P-values derived from independent t-test. $P^{\prime}$ : after adjusting for baseline value. $¥ P<0.001$ compared between two groups at 12 -week follow-up and $+P<0.05$, $t+P<0.001$ compared between two groups at changed values tested by independent $t$-test. 
$\Delta$ HDL-cholesterol

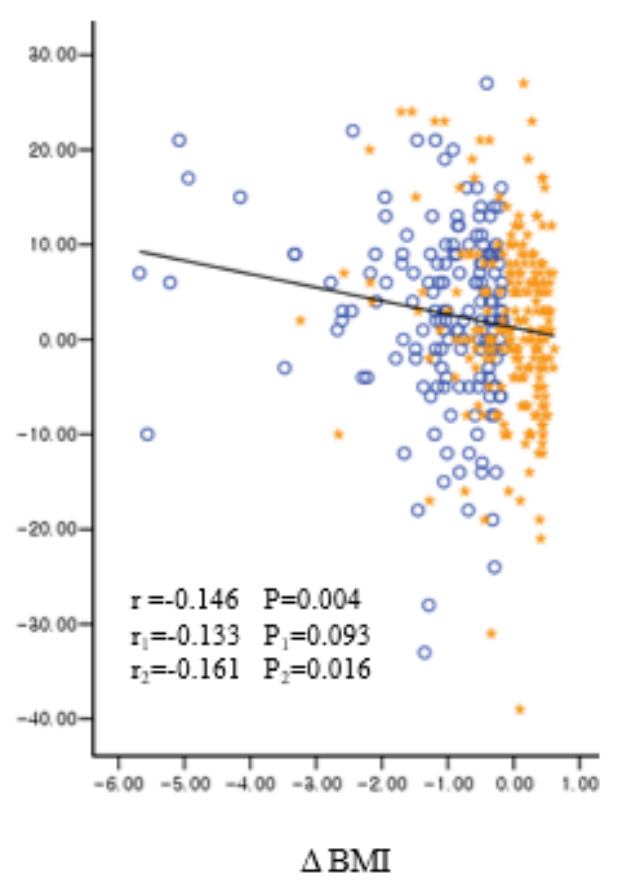

$\triangle$ HOMA-IR

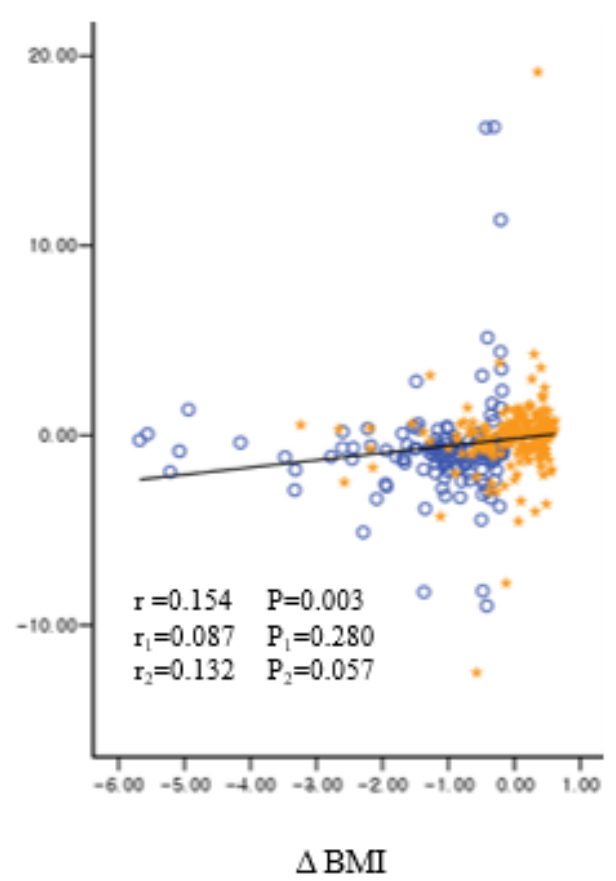

$\Delta \mathrm{BMI}$

\section{$\Delta$ Adiponectin}

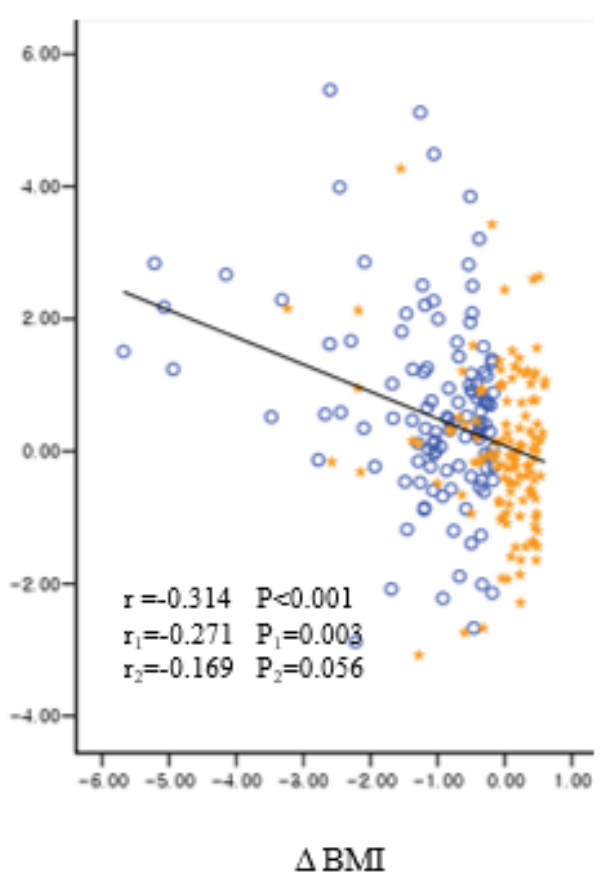

\section{Figure 2}

Correlations between changes (difference from baseline) in BMI, HDL-cholesterol, HOMA-IR index, and adiponectin in 383 subjects r: Pearson's correlation coefficients in total subjects. r1: correlation coefficients in HFD group. r2: correlation coefficients in LFD group. 